\title{
Suitability of Video Consultations During the COVID-19 Pandemic Lockdown: Cross-sectional Survey Among Norwegian General Practitioners
}

Tor Magne Johnsen ${ }^{1,2^{*}}$, MD; Børge Lønnebakke Norberg ${ }^{1,2^{*}}$, MD; Eli Kristiansen ${ }^{1}$, MSc; Paolo Zanaboni ${ }^{1,3}$, PhD; Bjarne Austad ${ }^{2}, \mathrm{MD}, \mathrm{PhD}$; Frode Helgetun Krogh ${ }^{1,2}$, MSc, MPBA; Linn Getz ${ }^{2}$, MD, PhD

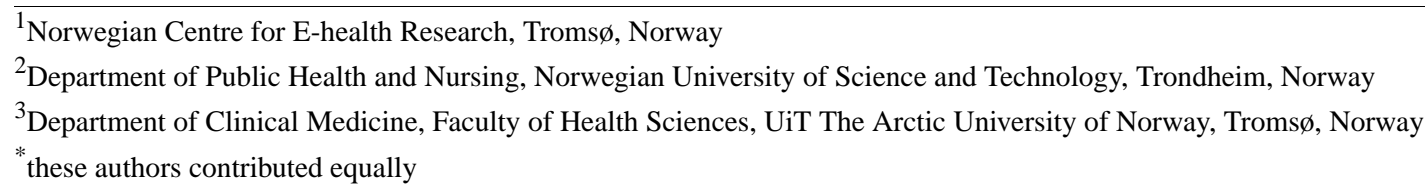

\section{Corresponding Author:}

Eli Kristiansen, MSc

Norwegian Centre for E-health Research

Sykehusveien 23

Troms $\varnothing, 9019$

Norway

Phone: 4797162311

Email: eli.kristiansen@ehealthresearch.no

\begin{abstract}
Background: The COVID-19 pandemic imposed an acute, sharp rise in the use of video consultations (VCs) by general practitioners (GPs) in Norway.

Objective: This study aims to document GPs' experiences with the large-scale uptake of VCs in the natural experiment context of the pandemic.

Methods: A nationwide, cross-sectional online survey was conducted among Norwegian GPs during the pandemic lockdown (April 14-May 3, 2020). Each respondent was asked to evaluate up to 10 VCs. Basic demographic characteristics of the GPs and their practices were collected. The associations between GPs' perceived suitability of the VCs, the nature of the patients' main problems, prior knowledge of the patients (relational continuity), and follow-up of previously presented problems (episodic continuity) were explored using descriptive statistics, diagrams, and chi-square tests.

Results: In total, 1237 GPs (26\% of the target group) responded to the survey. Among these, 1000 GPs offered VCs, and 855 GPs evaluated a total of 3484 VCs. Most GPs who offered VCs $(1000 / 1237 ; 81 \%)$ had no experience with VCs before the pandemic. Overall, 51\% (1766/3476) of the evaluated VCs were considered to have similar or even better suitability to assess the main reason for contact, compared to face-to-face consultations. In the presence of relational continuity, VCs were considered equal to or better than face-to-face consultations in 57\% (1011/1785) of cases, as opposed to 32\% (87/274) when the patient was unknown. The suitability rate for follow-up consultations (episodic continuity) was 61\% (1165/1919), compared to 35\% (544/1556) for new patient problems. Suitability varied considerably across clinical contact reasons. VCs were found most suitable for anxiety and life stress, depression, and administrative purposes, as well as for longstanding or complex problems that normally require multiple follow-up consultations. The GPs estimate that they will conduct about $20 \%$ of their consultations by video in a future, nonpandemic setting.

Conclusions: Our study of VCs performed in general practice during the pandemic lockdown indicates a clear future role for VCs in nonpandemic settings. The strong and consistent association between continuity of care and GPs' perceptions of the suitability of VCs is a new and important finding with considerable relevance for future primary health care planning.
\end{abstract}

(J Med Internet Res 2021;23(2):e26433) doi: 10.2196/26433

\section{KEYWORDS}

video consultations; digital consultations; eHealth; general practice; primary health care; continuity of care; physician-patient relationship; patient safety; COVID-19; pandemic; telehealth; telemedicine; consultation; safety; cross-sectional; online survey 


\section{Introduction}

\section{Background}

The digitalization of medical consultations in general practice (family medicine) has in many countries received increasing interest in recent years, with a particular focus on video consultations (VCs) [1-3]. However, the implementation of VCs by general practitioners (GPs) has been relatively slow and supported by limited and inconclusive evidence [4]. The emergence of the COVID-19 pandemic introduced an abrupt and strong stimulus for rapid adoption of VCs in many contexts, producing an effect that was arguably most striking in settings where a digitalization process had already started $[5,6]$.

Prepandemic research on VCs in general practice has mostly been characterized by small studies on selected patient groups $[7,8]$. Results indicate that VCs might be useful for selected patients or health problems and have the potential for increased patient empowerment, practical convenience, and efficiency gains $[9,10]$. However, concerns have been raised regarding the clinical quality and suitability of VCs, and both patients and clinicians still consider face-to-face consultations the gold standard [7,8,11,12]. More knowledge is needed about the optimal use of VCs in general practice, from both an organizational and a clinical perspective [13].

In the context of face-to-face consultations, continuity of care [14] has been associated with positive health outcomes for patients, including increased life expectancy $[15,16]$. There is little knowledge regarding the impact of $\mathrm{VCs}$ on the doctor-patient relationship and to what extent a pre-existing doctor-patient relationship might impact the quality and outcome of VCs. The introduction of VCs in situations where GPs deliver continuity of care to their patients (relational continuity) and are familiar with their ongoing health problems (episodic continuity) may have a positive impact compared to situations where continuity of care is not established [17].

\section{Use of VCs in Norway Before and During the COVID-19 Pandemic}

Before the COVID-19 pandemic, around 3\% of all GP consultations in Norway were performed digitally [18]. The societal lockdown in Europe in spring 2020 had a strong impact on general practice in Norway. On March 16, 2020, the Norwegian Ministry of Health and Care Services encouraged all GPs to adopt a solution for VCs [19]. The reimbursement system for GPs was also temporarily modified to strengthen the use of medical consultations via text, video, or telephone (Textbox 1). Data from the main providers of VC solutions showed that, while almost all 4822 GPs in Norway installed a solution for VCs, less than 2000 GPs used VCs during the period April 15-May 3, 2020.

During the first phase of the lockdown in mid-March 2020, many GP offices restricted physical access and triaged all contacts via telephone or online communication. Almost $60 \%$ $(171,169 / 299,148)$ of all GP consultations in Norway were performed digitally from March 16 to March 22 (Multimedia Appendix 1). In the last week of March, $25 \%(34,814 / 141,501)$ of all digital consultations were VCs (Multimedia Appendix 2). From May 11 to May 17, the proportion of digital consultations decreased to $30 \%(85,026 / 286,419)$, of which $19 \%$ $(16,278 / 85,026)$ were VCs.

Most GP offices still offered face-to-face consultations for urgent issues. However, digital consultations were conducted even in situations where a physical examination would have been deemed necessary before the COVID-19 lockdown, such as acute abdominal pain or chest pain. At the time of data collection, the main technical solution for VCs in Norway was an external video application not integrated with the GP's electronic patient record systems. However, the patients' medical record was available to the GPs during the VCs.

Textbox 1. The Norwegian General Practitioner Scheme.

The Norwegian health care system is based on the principles of universal access, decentralization, and continuity of care [20]. Since 2001, all Norwegian citizens may sign up with (and change, if desired) a GP, and $99 \%$ have chosen to do so. The system is financed by taxation, together with income-related employee and employer contributions and out-of-pocket payments (copayments). Private medical insurance is limited. Although national health care policy is controlled centrally, responsibility for the provision of primary health care is decentralized. GPs act as coordinators of municipal services and gatekeepers to specialized care. On average, a GP has about 1100 patients and often provides other medical services in the municipality one day per week

\section{Evaluation of VCs During the COVID-19 Pandemic}

In association with the COVID-19 pandemic, recommendations regarding the use of VCs by GPs and their patients have been issued based on clinical expertise and relevant evidence [13,21]. The lockdown led to a rapid uptake of VCs during a very short time period, creating a natural experiment where the effectiveness and suitability of VCs could be explored across a wide range of health problems [5].

Ideally, the large-scale implementation of VCs should have been rigorously monitored by detailed research on both GPs and patients. Due to the pressing circumstances of the lockdown, such systematic evaluation was not deemed feasible. However, conducting a large-scale survey of GPs' experiences with the use of VCs during the lockdown was achievable and can contribute to filling important knowledge gaps.

The overall aim of this survey was to explore how GPs in Norway perceived the suitability of VCs compared to ordinary face-to-face consultations during the COVID-19 lockdown. In addition to addressing the suitability of VCs across a wide range of health problems (reasons for contact), we were also interested in knowing whether continuity of care (ie, prior knowledge of the patient/problem) had an impact on GPs' perceptions of VC suitability. 


\section{Methods}

\section{Study Design and Setting}

A prospective nationwide online cross-sectional survey was conducted among GPs in Norway during the COVID-19 pandemic lockdown (April 14-May 3, 2020). The survey was addressed to all GPs registered in Norway. Basic demographic characteristics of the GPs and their practices were collected. Each GP also indicated the number of consultations and other activities conducted during the day when the survey was taken.

A central part of the survey addressed GPs' experiences with VCs before and during the pandemic. Each GP was asked to evaluate up to 10 consecutive (or otherwise unselected) VCs during the COVID-19 lockdown, preferably conducted during the same day. The evaluation of each VC included 13 questions that covered the GPs' prior knowledge of the patient (relational continuity), whether the reason for contact was a new problem or a follow-up (episodic continuity), the total number of presented problems, the nature of the main problem (as perceived by the GP), the perceived suitability of VC compared to an envisaged face-to-face consultation for the main problem, and actions (one or more) taken by the GP during/after the VC. The GP's perception of the patient's satisfaction with the VC, the technical quality of each $\mathrm{VC}$, and their willingness to use $\mathrm{VC}$ in a similar situation after the COVID-19 pandemic were also recorded. Finally, the GPs were asked to estimate the overall proportion of VCs they personally envisaged in their practice in a "normalized" future, in light of their accumulated experience with the medium.

Questions were multiple choice with 2-11 alternative answers, depending on the topic. Questions concerning users' experiences were scored on a 3-point or 4-point Likert scale. Regarding patients' reasons for contact, a total of 78 alternatives were offered. This list was informed by the International Classification of Primary Care, second edition (ICPC-2), but was less detailed. Regarding actions taken during or after each VC, 16 alternatives were offered. We consulted the Checklist for Reporting Results of Internet E-Surveys (CHERRIES) to develop the survey and report its results [22]. The survey was pilot tested by a panel of experienced GPs. The survey was conducted in Norwegian through the Netigate application. The results have been translated into English for the purpose of publication.

\section{Data Collection}

To obtain access to GPs' updated contact emails on very short notice, the research team collaborated with Norwegian Health Informatics, a web-based portal that hosts an online clinical decision support product (NEL), to which approximately $98 \%$ of all Norwegian GPs subscribe [23]. An invitation was sent to all subscribers by a unique link that ensured both the authenticity and anonymity of the respondents. GPs who did not receive a personal invitation by email or were nonsubscribers of NEL were encouraged by a well-established social media group for GPs to register their email addresses on the Norwegian Health Informatics website. It took approximately 30-60 minutes to complete the survey. Data collection was undertaken in the period April 14-May 3, 2020. Several reminders were sent by email and social media.

\section{Data Analysis}

Results were summarized by descriptive statistics, diagrams, and chi-square tests with $95 \%$ CIs. Background data from this survey were compared to available information on all GPs in Norway. The associations between suitability of VCs and relational continuity, episodic continuity, and the nature of the patients' main problems were explored by diagrams, tables, and chi-square tests. The defined significance level was .05.

Before further analysis was performed, the 78 alternative reasons for contact were merged into 27 more overarching categories (eg, knee, hip, shoulder, and back problems were merged into "musculoskeletal issues"). We also merged "better" and "same" into one category regarding suitability. Data were analyzed in IBM Statistical Package for the Social Sciences (SPSS; Version 26.0, IBM Corp).

\section{Ethics}

Ethical considerations were included in all phases of the survey. Participating GPs were informed that participation was voluntary and anonymous. We did not elicit sensitive information or demographic characteristics that could reveal the identity of the GPs. For the evaluated VCs, we did not elicit patients' age, sex, specific diagnoses, or other sensitive or person-related information. Distribution of the survey to GPs' email addresses was handled by an independent party (Norwegian Health Informatics). No linkage key was established, and participants' IP numbers were not accessible to any party. Further approvals were thereby not required, according to Norwegian health research legislation, verified by the Norwegian Centre for Research Data (NSD).

\section{Results}

\section{Characteristics of the GPs}

A total of 1237 GPs participated in the survey, representing $26 \%(1237 / 4822)$ of the total GP population in Norway [24]. Of these, $1000(81 \%)$ answered that they were equipped to offer VCs at the time of the survey, and 855 contributed evaluations of at least one VC (Table 1).

On average, each GP conducted 20 consultations during the surveyed working day. Of these, $6.9(34.5 \%)$ were face-to-face consultations, 5.3 (26.5\%) were VCs, 3.3 (16.5\%) were text-based e-consultations, and $4.5(22.5 \%)$ were telephone consultations. Of the 855 participants, 74 (9\%) had no face-to-face consultations on the study day. Most of the respondents $(80 \% ; 687 / 855)$ did not have any experience with the use of VCs before the COVID-19 pandemic. 
Table 1. Characteristics of the 855 general practitioners who evaluated one or more video consultations.

\begin{tabular}{|c|c|}
\hline Characteristics of the general practitioners $(\mathrm{N}=855)$ & Participants, n (\%) \\
\hline \multicolumn{2}{|l|}{ Gender } \\
\hline Female & $480(56.2)$ \\
\hline Male & $368(43.0)$ \\
\hline No answer & $7(0.8)$ \\
\hline \multicolumn{2}{|l|}{ Experience in years as a general practitioner } \\
\hline $0-5$ & $174(20.3)$ \\
\hline $6-10$ & $189(22.1)$ \\
\hline $11-20$ & $287(33.6)$ \\
\hline$>20$ & $205(24.0)$ \\
\hline \multicolumn{2}{|l|}{ Inhabitants of the municipality of practice } \\
\hline$<10,000$ & $130(15.2)$ \\
\hline $10,000-50,000$ & $295(34.5)$ \\
\hline $50,000-100,000$ & $143(16.7)$ \\
\hline $100,000-500,000$ & $217(25.4)$ \\
\hline$>500,000$ & $70(8.2)$ \\
\hline \multicolumn{2}{|c|}{ Experience with video consultations before the COVID-19 pandemic } \\
\hline None & $687(80.3)$ \\
\hline Limited (1-50 video consultations) & $123(14.4)$ \\
\hline Relatively good ( $>50$ video consultations) & $45(5.3)$ \\
\hline
\end{tabular}

\section{Description of the VCs}

On average, each GP provided an evaluation of 3.8 VCs. The final data set included 3484 unique VCs between GPs and patients (Table 2).

In most VCs (79\%; 2760/3484), the GP knew the patient well beforehand, while the GPs described only 8\% (276/3484) of the patients as previously unknown. More than half of the consultations $(55 \%$; 1921/3481) were a follow-up of a previous problem. On average, 1.9 (median 2.0) problems/issues were discussed during each consultation. Half of the VCs $(51 \%$;
1766/3476) were considered to have similar or even better suitability to assess the main reason for contact compared to face-to-face consultations. For 15\% (514/3476) of the VCs, the GPs expressed concern that they might not have detected potential signs of serious illness. The lack of opportunity to physically examine the patient was reported as a "major loss" or "some loss" in 25\% (884/3475) and 36\% (1232/3475) of the VCs, respectively. In 85\% (2967/3475) of cases, the GPs perceived that the patient was satisfied with the VC. The technical quality was considered good in $90 \%$ (3118/3475) of the VCs. Half of the GPs (1704/3475) considered it realistic to handle a similar issue by VC after the COVID-19 pandemic. 
Table 2. Characteristics of the 3484 recorded video consultations. Missing answers (ranging from 0-9 general practitioners per question) are not displayed.

\begin{tabular}{lr}
\hline Characteristics of the video consultations $(\mathrm{N}=3484)$ & Values, $\mathrm{n}(\%)$ \\
\hline General practitioner's pre-existing knowledge of the patient & $1788(51.3)$ \\
Very good & $972(27.9)$ \\
Good & $448(12.9)$ \\
Some & $276(7.9)$ \\
None & $1560(44.8)$ \\
Main reason for contact & $1921(55.1)$ \\
New problem & $1471(42.2)$ \\
Follow-up & $1930(55.4)$ \\
Total number of contact reasons discussed & $75(2.2)$ \\
1 & $1766(50.7)$ \\
$2-4$ & $1709(49.1)$ \\
$>4$ &
\end{tabular}

Suitability of video consultation to assess the severity of the main reason for contact compared to a face-to-face consultation
Better or same
$1767(50.7)$
Worse
$1709(49.1)$

Loss from not being able to examine the patient physically

No loss

Some loss

Major loss

Concern about not picking up signs of serious illness

Not worried

2009 (57.7)

Neutral

Worried

General practitioner's perception of patient satisfaction with video consultation
Very satisfactory
988 (28.4)
Satisfactory
1979 (56.8)
Unsatisfactory
368 (10.6)
Do not know
$140(4.0)$

General practitioner's satisfaction with technology (connection, sound, image)

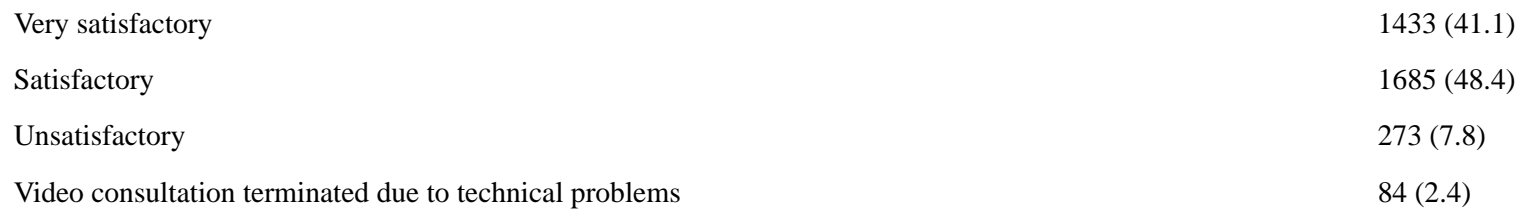

Motivation to conduct a video consultation for a similar health problem (reason for contact) in a nonpandemic future Yes

Do not know

$768(22.0)$

No 


\section{Suitability of VCs and Continuity of Care}

The association between GPs' perceptions of the suitability of VCs and their previous knowledge of their patients (relational continuity) is presented in Figure 1. When the GPs knew their patients "very well" beforehand, VCs were considered as having "better" or "same" suitability, compared to face-to-face consultations in $57 \%(1011 / 1785)$ of cases. When the patient was "unknown," the corresponding suitability rate dropped to $32 \%$ (87/274). The difference in proportions of better/same and worse suitability of VCs between the groups of relational continuity was statistically significant $\left(\chi_{3}^{2}=105.3, P<.001\right)$.

In Figure 2, we present the association between the GPs' perceptions of suitability of VCs and their previous knowledge of a given patient's presented problem (episodic continuity). VCs were considered better/same compared to envisaged face-to-face consultations in 61\% (1165/1919) of follow-up consultations, as opposed to $35 \%(544 / 1556)$ when the patient presented a new problem. The difference in proportions of better/same and worse suitability of VCs between the groups of episodic continuity was statistically significant $\left(\chi_{1}^{2}=227.9\right.$, $P<.001)$.

In Table 3, we have combined relational and episodic continuity of care. We present the proportion of VCs where the suitability is considered better or the same, compared to envisaged face-to-face consultations for the same contact reason. When the GP's prior knowledge of a patient was "very good" or "good" and the problem was a "follow-up," 62\% (1070/1719) of the VCs were considered equally or better suited than envisaged face-to-face consultations. The corresponding proportion drops to $30 \%(155 / 521)$ when the GP's prior knowledge of the patient was "some" or "none" and the problem was "new." The differences in proportion of the suitability of VCs in Table 3 are statistically significant $(P<.001)$.

Figure 1. Association between relational continuity (previous knowledge of the patient) and general practitioners' perceived suitability of video consultations compared to an envisaged face-to-face consultation for the same issue (95\% CIs are illustrated by lines). GP: general practitioner; VC: video consultation.

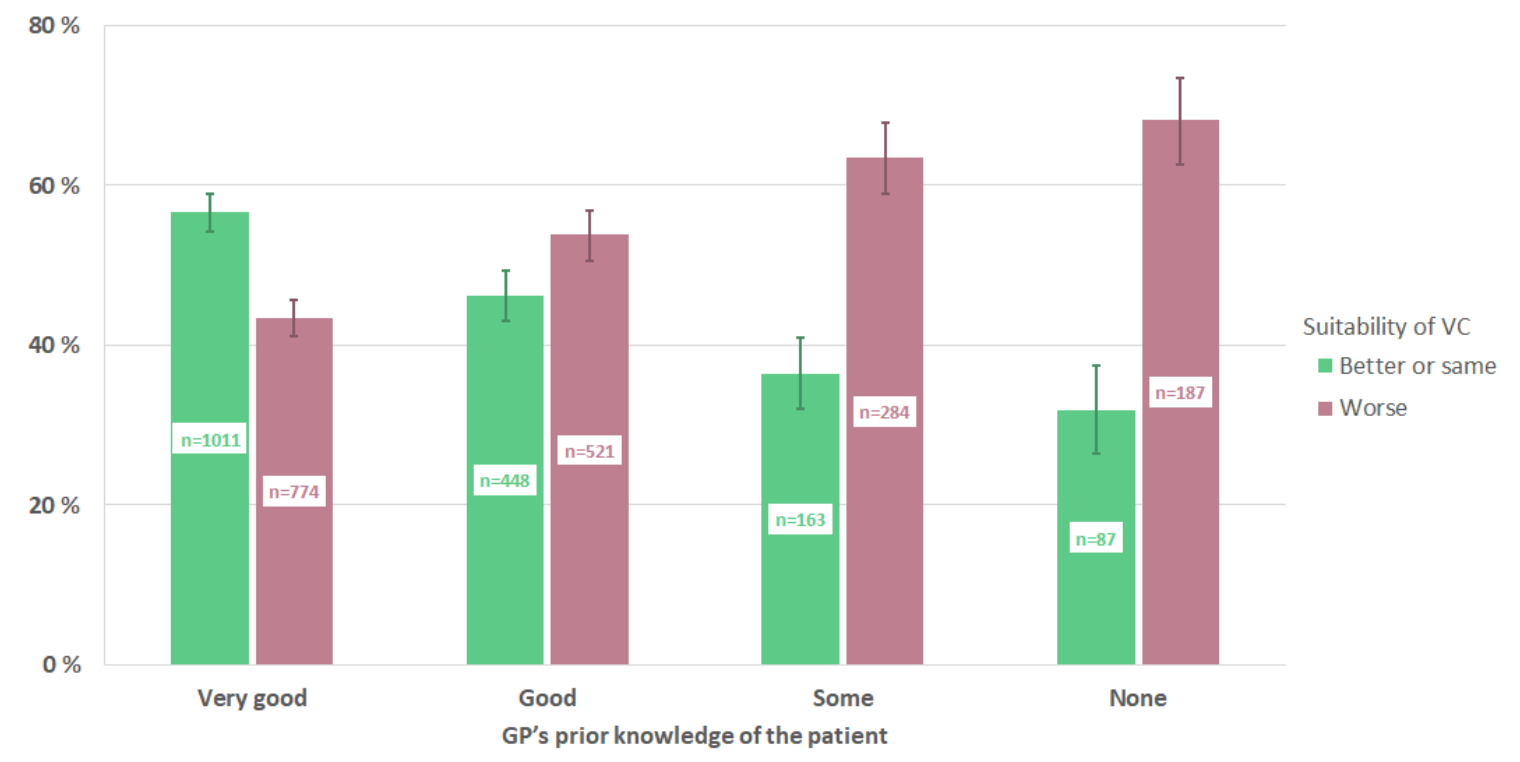


Figure 2. Association between episodic continuity (new problem or follow-up of previously defined problem) and general practitioners' perceived suitability of the video consultations, compared to envisaged face-to-face consultations for the same problem (95\% CIs are illustrated by lines). VC: video consultation.

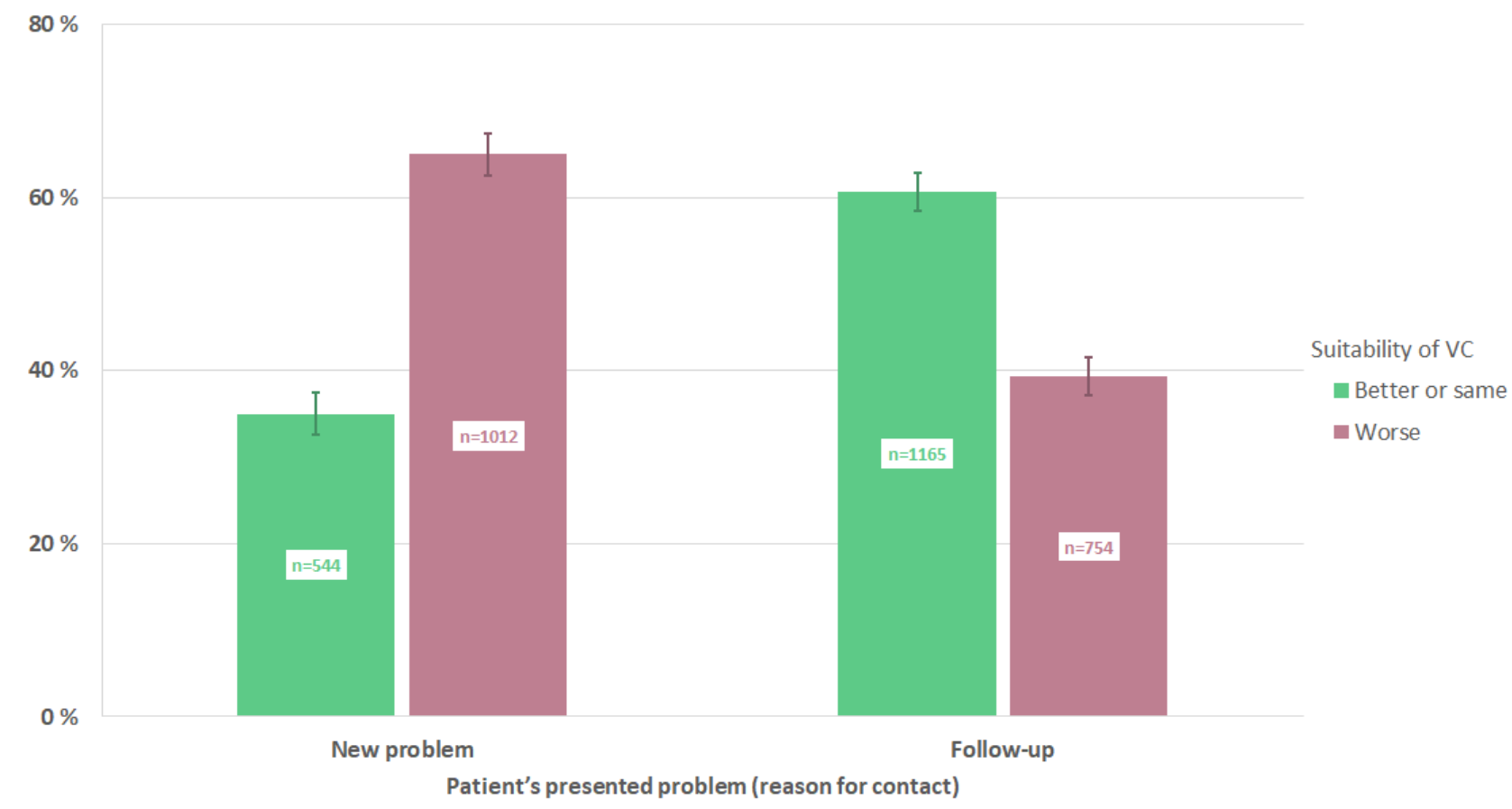

Table 3. Video consultations perceived by the GPs as equally or better suited compared to an envisaged face-to-face consultation, shown as combinations of pre-existing knowledge of the patient (relational continuity) and the main reason for contact (episodic continuity).

\begin{tabular}{lllll}
\hline Main reason for contact & $\begin{array}{l}\text { Pre-existing knowledge of patient } \\
\text { Very good/good ( } \mathrm{n}=2754)\end{array}$ & $\begin{array}{l}\text { Some/none }(\mathrm{n}=721) \\
\text { Number of video consultations, } \\
\end{array}$ & $\begin{array}{l}\text { Proportion, \% (95\% CI) } \\
\text { Number of video consultations, } \\
\mathrm{n} / \mathrm{N}\end{array}$ & Proportion, \% (95\% CI) \\
\hline New problem ( $\mathrm{n}=1556)$ & $389 / 1035$ & $38(35-41)$ & $155 / 521$ & $30(26-34)$ \\
Follow-up $(\mathrm{n}=1919)$ & $1070 / 1719$ & $62(60-65)$ & $95 / 200$ & $48(41-54)$ \\
\hline
\end{tabular}

\section{Suitability of VCs and Reasons for Contact}

GPs considered VCs to be equally or better suited for several reasons for contact, compared to envisaged face-to-face consultations (Figure 3); examples include mental illness/life stress $(509 / 684 ; 74 \%, 95 \%$ CI $71 \%-78 \%)$ and various administrative purposes (107/137; 78\%, 95\% CI $70 \%-84 \%)$.
On the other hand, other issues, including musculoskeletal problems $(187 / 469 ; 40 \%, 95 \%$ CI 36\%-44\%) and skin disorders (98/300; 33\%, 95\% CI 28\%-38\%), were regarded as less suitable for VCs. VCs were also considered less suitable in situations involving acute chest pain, stomach pain, and fear/investigation of a potential new cancer. 
Figure 3. General practitioners' perceived suitability of video consultations compared to an envisaged face-to-face consultation for the same issue, according to the nature of the main problem/reason for contact. The contact reasons are presented in decreasing frequency (n) from top to bottom, and 95\% CIs are illustrated by lines. VC: video consultation.

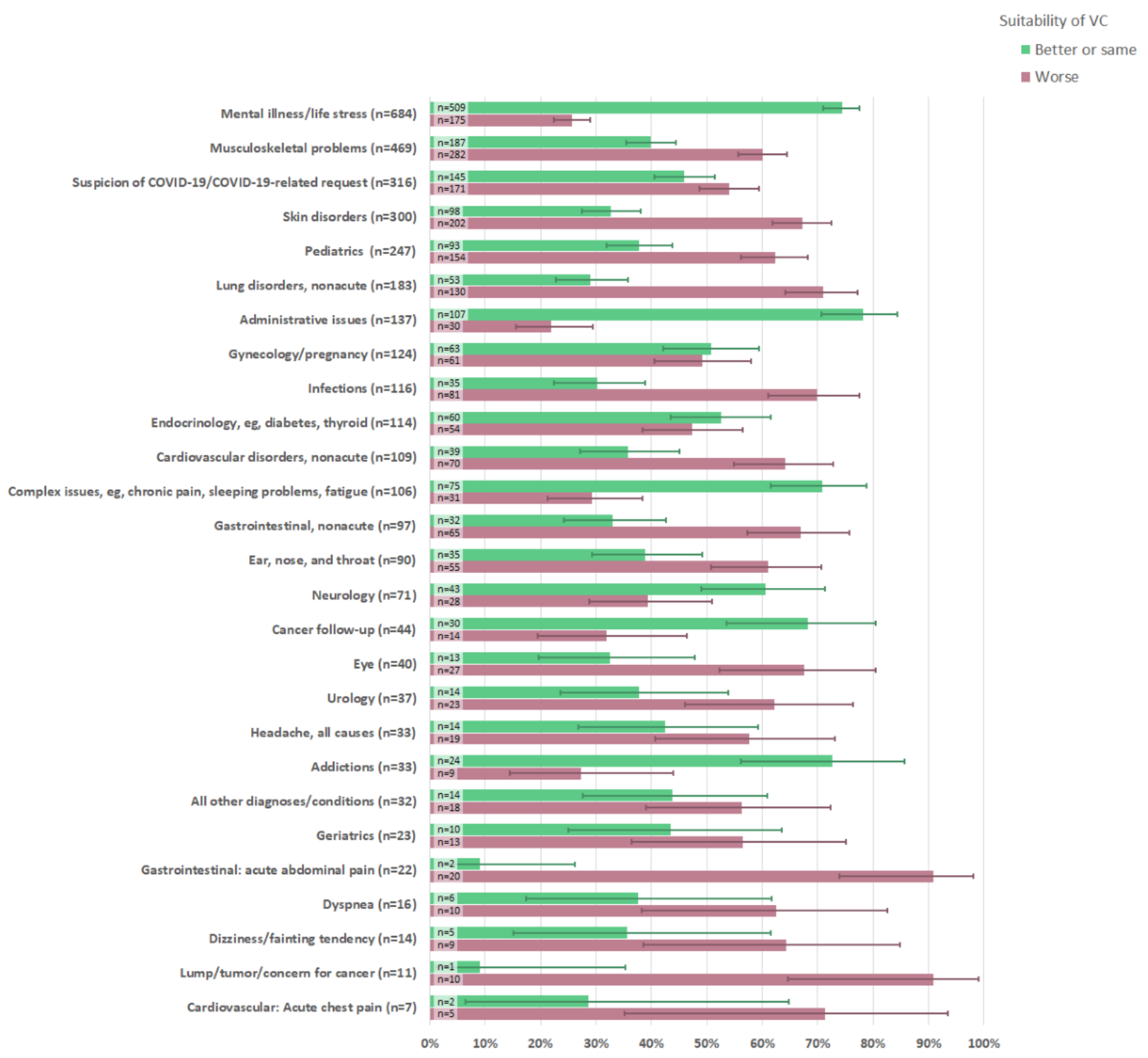

Furthermore, for each main reason for contact, the perceived suitability of VCs differed according to episodic continuity of care (Table 4). For instance, the suitability of VCs for skin disorders was 30\% (69/234) for a new problem and 44\% (29/66) for a previously discussed problem. Corresponding numbers were $18 \%(33 / 183)$ and $54 \%$ (154/286) for musculoskeletal problems, and 20\% (4/20) and 77\% (39/51) for neurology disorders. The impact of relational continuity of care on the suitability of VCs for individual health problems is not reported due to low statistical power (few unknown patients). 
Table 4. Suitability of video consultations compared to face-to-face consultations, association with main reason for contact (new problem/follow up), and the 20 most common issues/presented problems, $\mathrm{N}=3350$.

\begin{tabular}{|c|c|c|c|c|c|c|c|c|}
\hline \multirow[t]{4}{*}{ Issue/presented problem } & \multicolumn{8}{|c|}{ Main reason for contact } \\
\hline & \multicolumn{4}{|c|}{ New problem $(n=1484)$} & \multicolumn{4}{|c|}{ Follow-up (n=1866) } \\
\hline & \multicolumn{2}{|c|}{ Better or same $(n=529)$} & \multicolumn{2}{|c|}{ Worse $(n=955)$} & \multicolumn{2}{|c|}{ Better or same $(n=1140)$} & \multicolumn{2}{|c|}{ Worse $(n=726)$} \\
\hline & $\begin{array}{l}\text { Contacts, } \\
\mathrm{n} / \mathrm{N}\end{array}$ & $\begin{array}{l}\text { Proportion, } \\
\%(95 \% \mathrm{CI})\end{array}$ & $\begin{array}{l}\text { Contacts, } \\
\mathrm{n} / \mathrm{N}\end{array}$ & $\begin{array}{l}\text { Proportion, } \\
\%(95 \% \mathrm{CI})\end{array}$ & $\begin{array}{l}\text { Contacts, } \\
\mathrm{n} / \mathrm{N}\end{array}$ & $\begin{array}{l}\text { Proportion, } \\
\%(95 \% \mathrm{CI})\end{array}$ & $\begin{array}{l}\text { Contacts, } \\
\mathrm{n} / \mathrm{N}\end{array}$ & $\begin{array}{l}\text { Proportion, } \\
\%(95 \% \mathrm{CI})\end{array}$ \\
\hline Mental illness/life stress & $67 / 105$ & $64(54-73)^{\mathrm{a}}$ & $38 / 105$ & $36(28-46)^{\mathrm{a}}$ & $442 / 579$ & $76(73-80)^{\mathrm{a}}$ & $137 / 579$ & $24(20-27)^{\mathrm{a}}$ \\
\hline Musculoskeletal problems & $33 / 183$ & $18(13-24)^{\mathrm{a}}$ & $150 / 183$ & $82(76-87)^{\mathrm{a}}$ & $154 / 286$ & $54(48-60)$ & $132 / 286$ & $46(40-52)$ \\
\hline $\begin{array}{l}\text { Suspicion of COVID-19 or COVID- } \\
\text { 19-related }\end{array}$ & $99 / 222$ & $45(38-51)$ & $123 / 222$ & $55(49-62)$ & $46 / 94$ & $49(39-59)$ & $48 / 94$ & $51(41-61)$ \\
\hline Skin disorders & $69 / 234$ & $30(24-36)^{\mathrm{a}}$ & $165 / 234$ & $71(64-76)^{\mathrm{a}}$ & $29 / 66$ & $44(32-56)$ & $37 / 66$ & $56(44-68)$ \\
\hline Children & $52 / 173$ & $30(24-37)^{\mathrm{a}}$ & $121 / 173$ & $70(63-76)^{\mathrm{a}}$ & $41 / 74$ & $55(44-66)$ & $33 / 74$ & $45(34-56)$ \\
\hline Lung & $27 / 96$ & $28(20-38)^{\mathrm{a}}$ & $69 / 96$ & $72(62-80)^{\mathrm{a}}$ & $26 / 87$ & $30(21-40)^{\mathrm{a}}$ & $61 / 87$ & $70(60-79)^{\mathrm{a}}$ \\
\hline Administrative issues & $45 / 57$ & $79(67-88)^{\mathrm{a}}$ & $12 / 57$ & $21(12-33)^{\mathrm{a}}$ & $62 / 80$ & $78(68-86)^{\mathrm{a}}$ & $18 / 80$ & $23(14-33)^{\mathrm{a}}$ \\
\hline Gynecology and pregnancy & $24 / 50$ & $48(35-62)$ & $26 / 50$ & $52(38-65)$ & $39 / 74$ & $53(41-64)$ & $35 / 74$ & $47(36-59)$ \\
\hline Infection & $25 / 84$ & $30(21-40)^{\mathrm{a}}$ & $59 / 84$ & $70(60-79)^{\mathrm{a}}$ & $10 / 32$ & $31(17-48)$ & $22 / 32$ & $69(52-83)$ \\
\hline Endocrinology & $6 / 15$ & $40(19-65)$ & $9 / 15$ & $60(35-81)$ & $54 / 99$ & $55(45-64)$ & $45 / 99$ & $46(36-55)$ \\
\hline Cardiovascular & $2 / 37$ & $19(9-34)^{\mathrm{a}}$ & $30 / 37$ & $81(66-91)^{\mathrm{a}}$ & $32 / 72$ & $44(33-56)$ & $40 / 72$ & $56(44-67)$ \\
\hline Complex issues and disorders & $10 / 20$ & $50(29-71)$ & $10 / 20$ & $50(29-71)$ & $65 / 86$ & $76(66-84)^{\mathrm{a}}$ & $21 / 86$ & $24(16-34)^{\mathrm{a}}$ \\
\hline Gastrointestinal & $12 / 47$ & $26(15-39)^{\mathrm{a}}$ & $35 / 47$ & $75(61-85)^{\mathrm{a}}$ & $20 / 50$ & $40(27-54)$ & $30 / 50$ & $60(46-73)$ \\
\hline ENT (ear, nose, and throat) & $23 / 68$ & $34(23-46)^{\mathrm{a}}$ & $45 / 68$ & $66(54-77)^{\mathrm{a}}$ & $12 / 22$ & $55(34-74)$ & $10 / 22$ & $46(26-66)$ \\
\hline Neurology & $4 / 20$ & $20(7-41)^{\mathrm{a}}$ & $16 / 20$ & $80(59-93)^{\mathrm{a}}$ & $39 / 51$ & $77(64-86)^{\mathrm{a}}$ & $12 / 51$ & $24(14-36)^{\mathrm{a}}$ \\
\hline Cancer follow-up & $2 / 3$ & $67(18-96)$ & $1 / 3$ & $33(4-82)$ & $28 / 41$ & $68(53-81)^{\mathrm{a}}$ & $13 / 41$ & $32(19-47)^{\mathrm{a}}$ \\
\hline Eye & $12 / 36$ & $33(20-50)^{\mathrm{a}}$ & $24 / 36$ & $67(51-80)^{\mathrm{a}}$ & $1 / 4$ & $25(3-72)$ & $3 / 4$ & 75 (28-97) \\
\hline Urology & $9 / 22$ & $41(23-62)$ & $13 / 22$ & $59(39-78)$ & $5 / 15$ & $33(14-58)$ & $10 / 15$ & $67(42-86)$ \\
\hline Headache & $1 / 8$ & $13(1-45)^{\mathrm{a}}$ & $7 / 8$ & $88(55-99)^{\mathrm{a}}$ & $13 / 25$ & $52(33-71)$ & $12 / 25$ & $48(30-67)$ \\
\hline Intoxication and addiction & $2 / 4$ & $50(12-88)^{\mathrm{a}}$ & $2 / 4$ & $50(12-88)^{\mathrm{a}}$ & $22 / 29$ & $76(58-89)^{\mathrm{a}}$ & $7 / 29$ & $24(12-42)^{\mathrm{a}}$ \\
\hline
\end{tabular}

${ }^{\mathrm{a}}$ Nonoverlapping CIs.

\section{Suitability of VCs and Actions Taken in the VCs}

A total of 7647 actions were registered by the GP during/after the VCs (Table 5). The most common action (47\%; 1646/3476) was "comprehensive advice and guidance," followed by planning a new VC or text-based e-consultation (34\%; 1197/3476).
VCs were deemed to be less suitable in situations where a physical follow-up was subsequently planned (ie, a face-to-face consultation in the near future, referrals to medical imaging, laboratory examinations, and hospitalizations; Figure 4). Prescription of antibiotics or new medications were also situations where VCs were considered less suitable. Conversely, VCs were perceived as suitable for prolonging sick leaves. 
Table 5. Action taken during/after the 3484 evaluated video consultations. Several actions could be registered for each video consultation. ${ }^{\text {a }}$

\begin{tabular}{lll}
\hline Type of actions taken during/after the video consultation $(\mathrm{N}=7647)$ & Count, $\mathrm{n}$ & $\%$ \\
\hline Comprehensive advice and guidance & 1646 & 47 \\
Planning a new video consultation or text-based e-consultation & 1197 & 34 \\
Prolongation of sick leave certificate & 791 & 23 \\
Planning of face-to-face consultation some time ahead & 486 & 14 \\
Prescription of new medication & 429 & 12 \\
Referral to laboratory testing & 425 & 12 \\
Renewal of established medication & 408 & 12 \\
Referral to other medical specialists (nonacute) & 395 & 11 \\
New sick leave certificate & 391 & 11 \\
No new appointment made; contact doctor if needed & 390 & 11 \\
Planning of face-to-face consultation in near future & 388 & 11 \\
Various other actions & 268 & 8 \\
Prescription of antibiotics & 145 & 4 \\
Referral to medical imaging & 119 & 3 \\
Prescription of sedatives or hypnotics (addictive drugs) & 90 & 3 \\
Hospitalization or acute referral & 79 & 2 \\
\hline
\end{tabular}

${ }^{a}$ In total, 8 evaluated video consultations did not have a registered action. 
Figure 4. Associations between general practitioners' perceived suitability of video consultations and actions taken during/after the consultation. The actions taken are sorted by general practitioners' perceived suitability (better or same) of the video consultation in question, displayed in decreasing order. 95\% CIs are illustrated by lines. VC: video consultation.

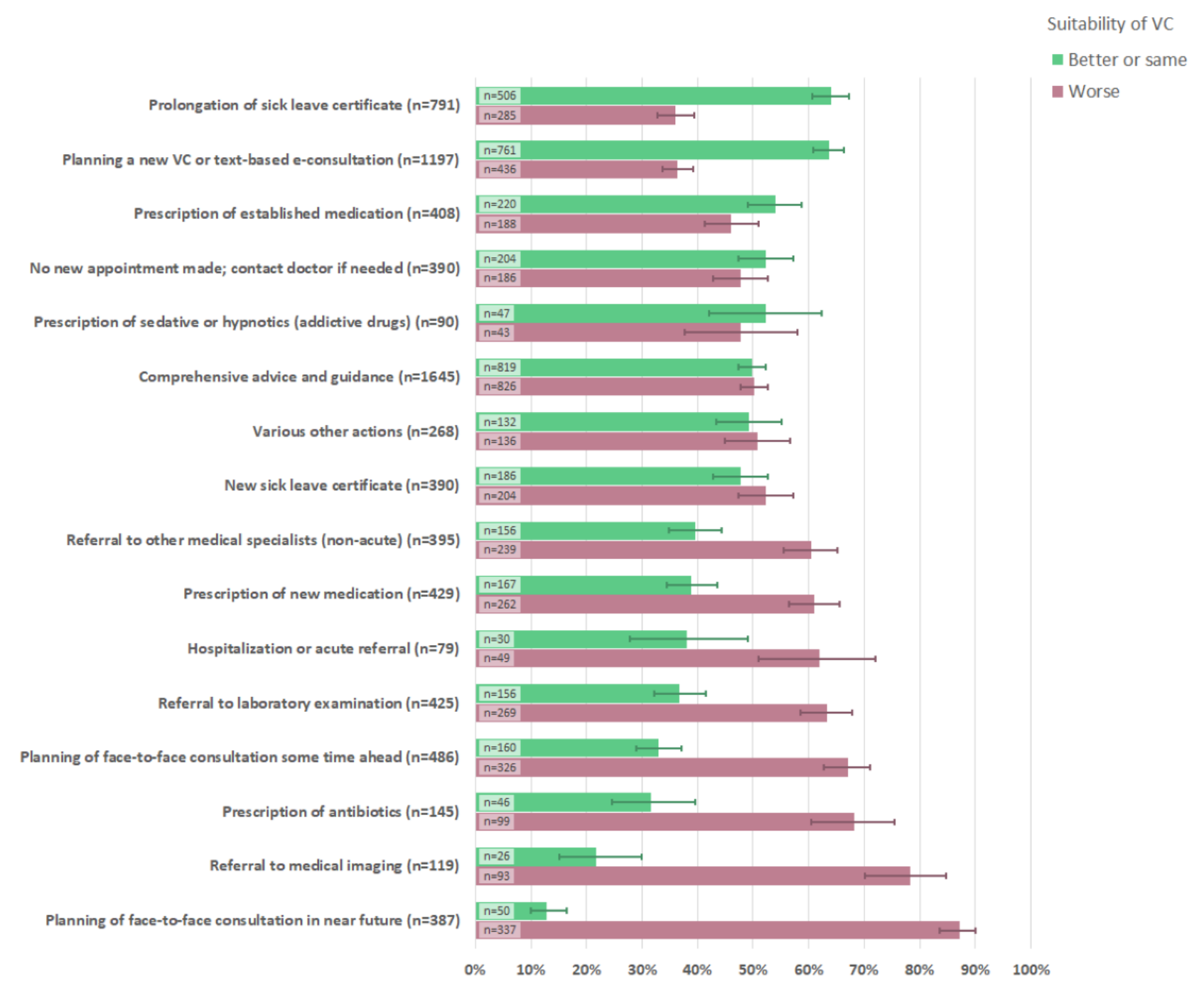

\section{Envisaging the Place for VCs in a Normalized Future}

Based on their accumulated experience with VCs, participating GPs estimated that on average, $19 \%$ of all their consultations (median 20\%) could be conducted via video in a normalized, nonpandemic future. Further analyses showed that this estimate was not associated with the GP's geographic context, previous experience with VCs, age, or gender.

\section{Discussion}

\section{Principal Findings}

This online, cross-sectional survey conducted among GPs in Norway during the COVID-19 pandemic lockdown provides new knowledge about GPs' experiences with large-scale uptake of VCs within the context of an established national primary health care system. Data collection took place in a phase of the lockdown when infection rates had peaked and most GPs had adapted their working practices, including implementation of VCs, to the pandemic circumstances.
Overall, VCs were perceived as equally or even more suitable than face-to-face consultations in about half of the 3484 evaluated cases. VCs appeared significantly more appropriate in the context of an established doctor-patient relationship and in relation to a previously defined reason for contact. GPs expressed concern about immediate patient safety (ie, the risk of missing signs of serious disease) in 15\% (514/3476) of the evaluated cases.

\section{Validating the Concept of Suitability}

Most of the survey was developed around the perceived suitability of VCs in general practice, compared to ordinary face-to-face consultations. It was therefore essential to ensure that the participating GPs had a shared understanding of the concept of suitability. Face validity of the term was assessed when the survey was pilot tested and was found to be satisfactory. Moreover, GPs were instructed to evaluate the suitability of VCs without emphasis on the evident gain of reducing the risk of viral contamination. Furthermore, the analysis of the association between perceived suitability and actions taken in the VCs contributed to the validation of the 
suitability concept. Consultations categorized with low suitability for VCs often had an "unfinished" character, thus requiring further clinical investigations and/or referrals that could have been more effectively managed in an ordinary face-to-face consultation (Figure 4).

\section{Impact of Continuity of Care on the Perceived Suitability of VCs}

A central finding in this survey was a strong and consistent association between both relational and episodic continuity of care and GPs' perceptions of the suitability of VCs (Figures 1 and 2, Tables 3 and 4). When GPs knew the patients very well beforehand, VCs were considered equally or better suited than face-to-face consultations in 57\% (1011/1785) of cases, as opposed to $32 \%(87 / 274)$ when the patient was previously unknown. Moreover, the suitability rate for follow-up consultations was $61 \%(1165 / 1919)$, while for new problems it was $35 \%$ (544/1556). It is important to note that these findings arose within the Norwegian GP list system and that the patient was totally new to the GP in only $8 \%$ (276/3484) of the evaluated VCs. To our knowledge, our study presents the first large-scale analysis of the impact of continuity of care on GPs' perceptions regarding the clinical suitability of VCs. It remains to be seen whether the quantifiable, beneficial outcomes of continuity of care found in physical consultation settings can be replicated in relation to VCs. Beyond this question, our results are in good accordance with previous findings, deliberations, and recommendations regarding quality potentials and pitfalls related to VCs [10,21,25,26].

\section{Suitability of VCs for Specific Contact Reasons}

The predefined list of medical issues used to categorize the main contact reason (presented problem) for each evaluated VC was developed for the purpose of this survey to provide a clinically relevant overview while being general enough to safeguard patient anonymity. We acknowledge that the opportunity to categorize only one (perceived by the GP as the main) reason for contact underrates the clinical complexity of the evaluated VCs, as many of them dealt with two or more health problems (Table 2). In our VC material, mental problems and life stress, musculoskeletal disorders, and COVID-19-related contacts occurred most frequently. When most countries in Europe imposed a lockdown in March 2020, VCs were predicted to be potentially useful for consulting about COVID-19 for people with heightened anxiety, mild symptoms suggestive of COVID-19, or more severe symptoms [13]. The results from our survey confirm these predictions.

Moreover, under the given circumstances, we found that VCs were suitable for a variety of mental health problems, along with other chronic or complex issues such as chronic pain, tiredness, sleeping problems, follow-up of established cancer treatment, and administrative purposes (Figure 3). These results are also in line with previous expectations that VCs could replace in-person visits for contacts related to chronic disease reviews, counselling, or other talking therapies, or administrative appointments such as sick leave certificates [13,27]. Chronic and complex problems are prevalent in general practice and typically involve several consultations with the GP over time [28]. In the presence of continuity of care, such problems can typically be handled in a collaborative dialogical process between doctor and patient. Further research might elucidate to what extent effective clinical relationships can be established and maintained through VCs.

Contacts related to skin problems, pediatric issues, and acute and potentially severe health problems (such as abdominal pain, chest pain, and respiratory difficulties) were found to be the least suitable for VCs. Real-time video might be a feasible alternative to face-to-face and store-and-forward (asynchronous) consultations for selected skin issues [29,30]. However, the evidence regarding the diagnostic accuracy of VCs is still weak [30]. Particular caution must be shown in situations where patient safety might be at risk, including the evaluation of potential malignancy [29-31]. Figure 3 provides an informative overall overview of GPs' perceived suitability of VCs for various contact reasons, but there is a clear need for more research to refine the knowledge about suitability for VCs in a normalized setting.

Our material included only 23 cases where the main problem was categorized as "geriatric," and the majority of these cases were classified with low suitability for VC. This aligns well with previous concerns that VCs may not be suitable for use by frail, older patients [8]. Overall, we believe that our results regarding clinical suitability are in good accordance with previous research and recommendations for VCs [13,26], as well as with a recent paper on the interpretative and contextualized nature of diagnostic "knowing" in general practice [32].

\section{Characteristics of the GPs}

Our study participants constitute approximately $26 \%$ (1237/4822) of all registered GPs in Norway. Their demographic characteristics are well representative of the GP population in Norway, with the exception of a slightly higher representation of younger doctors [24]. Since the survey was distributed through a unique link to each respondent, multiple responses from the same source can be ruled out.

Before deciding to participate in the survey, invited GPs were informed that VCs would be a central topic, but not a prerequisite for participation. This may nonetheless have attracted GPs with a positive attitude toward digital solutions. As mentioned in the introduction, many GPs who acquired VC equipment in relation to the pandemic lockdown hardly used it in practice. As previously argued, the implementation of VCs is not mainly a simple question of equipment installation, but a complex process of integrating a new consultation modality into established working routines [33]. As explained in the introduction, our estimates suggest that almost $50 \%$ of Norwegian GPs who used VCs in April 2020 participated in this survey, which is a clear strength.

\section{Selection Mechanisms Behind the Evaluated VCs}

On average, each participating GP performed five VCs on the day of the survey, while typically evaluating three of these. The survey instructed the GPs not to purposefully select particular types of VCs for evaluation. Although we cannot rule out possible selection bias, it is unlikely that GPs would deliberately 
restrict their contribution to specific cases. The risk of substantial confirmation bias is therefore considered low.

However, other important selection mechanisms may have influenced our VC material. The study was undertaken in a lockdown period when patients were typically recommended to consult their GPs digitally or by phone before a physical consultation could be considered. In some GP offices, patients could book a VC directly through an online booking system. Beyond this, there were no formal guidelines on how to select patients for VCs. Irrespective of variations in booking systems, many GP offices would arrange physical consultations for selected urgent health problems. Nevertheless, our material includes numerous cases that would normally be considered poorly suited for VC (eg, acute abdomen and chest pain). This aligns well with the fact that participating GPs relatively often reported that they missed the opportunity to perform a physical examination (61\% of cases) or expressed concern that they might have misjudged the severity of the presented health problem ( $15 \%$ of cases). Our results cannot be generalized to the use of VCs under nonpandemic circumstances, but we believe they have substantial external validity.

\section{Current Status and Future Perspectives}

The COVID-19 pandemic has led to a crisis for many people and organizations worldwide. At the same time, it has offered opportunities to rethink what is important in general practice and really put new consultation modalities to the test [34]. Overall, our study indicates that VCs have a definite role in future general practice. A crucial question is how to apply VCs to appropriate purposes in an organizationally sustainable manner. On the positive side, VCs can facilitate access and provide rapid solutions in well-selected situations. They can also enhance access to care for disadvantaged or vulnerable patients who are digitally literate but reluctant to visit the GP office. On the flip side, too liberal a use of digital consultations may contribute to a more transactional and less relational way of dealing with deeply human issues, potentially undermining the health-promoting potential of person-centered, longitudinal care $[17,25]$. Furthermore, it is important to monitor the impact of the implementation of digital consultation modalities on the total clinical workload [35,36]. Patients' thresholds for contacting the GP for self-limiting conditions may decrease when digital options are easily accessible. Ineffective selection of cases for VCs might trigger physical follow-up consultations for the same problem, leading to increased workloads without associated clinical benefit.
In our study, GPs experienced technical difficulties in $10 \%$ of the consultations, somewhat less than a comparable study performed in New York City in March 2020, where technical problems were reported in $13 \%$ of consultations [37]. This indicates that more seamless integration of VCs with GPs' electronic record systems still remains a priority. Despite some technical challenges, the GPs reported that $85 \%$ of the patients seemed satisfied with the VCs, in accordance with existing knowledge on patient experience with VCs $[9,37,38]$. In about half the consultations, the GPs in our survey also deemed it realistic to handle a similar issue by $\mathrm{VC}$ in a future, normalized situation. At first glance, this might reflect a strong belief in digitalized health care. However, our findings emerged in an extraordinary setting, where many patients and GPs reportedly felt gratitude for being able to "see" each other at all, despite the ominous threat of contagion and dramatic lockdown measures.

Comparison of clinical practice during lockdown with practice-as-usual reveals numerous discrepancies, both obvious and subtle [39]. Experience-based insight into these differences and their impact on the effectiveness and quality of care is likely to explain why the typical GP in our survey envisaged conducting only about $20 \%$ of consultations by video in a normalized future. This prediction is substantially lower than the level of enthusiasm otherwise reflected in our material but would nevertheless represent an important organizational leap for Norwegian general practice as a whole.

\section{Conclusion}

Our study of VCs performed in Norwegian general practice during the pandemic lockdown indicates a future role for VCs in future, nonpandemic settings. The strong and consistent association between continuity of care and GPs' perceptions of the suitability of VCs is a new and important finding with considerable relevance for future primary health care planning. In accordance with existing literature and guidance, GPs' perceived suitability of VCs varied considerably across reasons for contact and presented health problems. The findings cannot be directly generalized beyond the specific context of the pandemic lockdown, but nevertheless provide interesting results regarding the performance of VCs for different reasons for contact and clinical conditions. The results indicate that GPs still consider the physical examination a crucial element of many consultations to enhance both diagnostic accuracy and quality of care in a wider sense. Reflecting on the accumulated experience with VCs, most participating GPs envisaged conducting $20 \%$ of their consultations by video in a future, nonpandemic setting.

\section{Acknowledgments}

After the survey was conducted, TMJ and BLN held part-time positions at the Norwegian Centre for E-health Research in Troms $\emptyset$, Norway. FLO 2.0 (a GP-driven, nonprofit organization dedicated to the sustainable development of Norwegian general practice) covered the license to Netigate.

Norwegian Health Informatics made a crucial contribution with the dispatch of the survey through their subscriber email list and website. The Norwegian Directorate of eHealth and Confrere provided background data on video consultations. 


\section{Authors' Contributions}

TMJ and NLB developed the survey together with LG, FHK, and BA. EK and PZ subsequently joined the team and contributed substantially to data analysis, interpretation of results, and writing, together with the rest of the authors.

\section{Conflicts of Interest}

The authors declare no conflicts of interests. The commercial actors who distributed the survey (Norwegian Health Informatics) and contributed information on the use of VCs in Norway in spring 2020 (Confrere) were at no point involved in the design of the survey or data analysis.

\section{Multimedia Appendix 1}

Consultations with general practitioners in Norway during the COVID-19 lockdown. The shaded period corresponds to the period of the data collection. April 6-12, 2020, was the Easter holiday week. Data obtained from Norwegian general practitioners' reimbursement claims and The Norwegian Directorate of eHealth.

[PNG File, 53 KB-Multimedia Appendix 1]

\section{Multimedia Appendix 2}

Digital consultations with general practitioners in Norway during the COVID-19 lockdown. The shaded period corresponds to the period of data collection. April 6-12, 2020, was the Easter holiday week. Data from Norwegian general practitioners' reimbursement claims and The Norwegian Directorate of eHealth.

[PNG File, 154 KB-Multimedia Appendix 2]

\section{References}

1. Digital First Primary Care. NHS England. URL: https://www.england.nhs.uk/gp/digital-first-primary-care/ [accessed 2021-01-25]

2. Scotland's digital health and care strategy: enabling, connecting and empowering. Scottish Government. 2018. URL: https:/ /www.gov.scot/publications/scotlands-digital-health-care-strategy-enabling-connecting-empowering/ [accessed 2021-01-25]

3. Helsedirektoratet, Direktoratet for e-helse. E-konsultasjon hos fastlege og legevakt [E-consultations with the GP and the emergency room] 2018. URL: https://www.helsedirektoratet.no/rapporter/ e-konsultasjon-helsedirektoratet-og-direktoratet-for-e-helse [accessed 2021-01-25]

4. Atherton H, Brant H, Ziebland S, Bikker A, Campbell J, Gibson A, et al. The potential of alternatives to face-to-face consultation in general practice, and the impact on different patient groups: a mixed-methods case study. Health Serv Deliv Res 2018 Jun;6(20):1-200. [doi: 10.3310/hsdr06200] [Medline: 29889485]

5. Greenhalgh T, Wherton J, Shaw S, Morrison C. Video consultations for COVID-19. BMJ 2020 Mar 12;368:m998. [doi: 10.1136/bmj.m998] [Medline: 32165352]

6. Webster P. Virtual health care in the era of COVID-19. The Lancet 2020 Apr;395(10231):1180-1181. [doi: 10.1016/s0140-6736(20)30818-7]

7. Mold F, Hendy J, Lai Y, de Lusignan S. Electronic Consultation in Primary Care Between Providers and Patients: Systematic Review. JMIR Med Inform 2019 Dec 03;7(4):e13042 [FREE Full text] [doi: 10.2196/13042] [Medline: $\underline{31793888]}$

8. Thiyagarajan A, Grant C, Griffiths F, Atherton H. Exploring patients' and clinicians' experiences of video consultations in primary care: a systematic scoping review. BJGP Open 2020 Mar 17;4(1):bjgpopen20X101020. [doi: 10.3399/bjgpopen20x101020]

9. Atherton H, Brant H, Ziebland S, Bikker A, Campbell J, Gibson A, et al. Alternatives to the face-to-face consultation in general practice: focused ethnographic case study. Br J Gen Pract 2018 Jan 29;68(669):e293-e300. [doi: 10.3399/bjgp18x694853]

10. Mueller M, Knop M, Niehaves B, Adarkwah CC. Investigating the Acceptance of Video Consultation by Patients in Rural Primary Care: Empirical Comparison of Preusers and Actual Users. JMIR Med Inform 2020 Oct 22;8(10):e20813 [REE Full text] [doi: 10.2196/20813] [Medline: 32969339]

11. Randhawa RS, Chandan JS, Thomas T, Singh S. An exploration of the attitudes and views of general practitioners on the use of video consultations in a primary healthcare setting: a qualitative pilot study. Prim Health Care Res Dev 2018 Jun 18;20:1. [doi: 10.1017/s1463423618000361]

12. Powell RE, Henstenburg JM, Cooper G, Hollander JE, Rising KL. Patient Perceptions of Telehealth Primary Care Video Visits. Ann Fam Med 2017 May 08;15(3):225-229 [FREE Full text] [doi: 10.1370/afm.2095] [Medline: 28483887]

13. Greenhalgh T, Morrison C, Choon G. Video consultations: a guide for practice 2020. URL: https://bjgplife.com/2020/03/ 18/video-consultations-guide-for-practice/ [accessed 2021-01-25]

14. Saultz JW. Defining and measuring interpersonal continuity of care. Ann Fam Med 2003 Sep 01;1(3):134-143 [FREE Full text] [doi: 10.1370/afm.23] [Medline: 15043374$]$ 
15. Pereira Gray DJ, Sidaway-Lee K, White E, Thorne A, Evans PH. Continuity of care with doctors-a matter of life and death? A systematic review of continuity of care and mortality. BMJ Open 2018 Jun 28;8(6):e021161 [FREE Full text] [doi: 10.1136/bmjopen-2017-021161] [Medline: 29959146]

16. Starfield B, Shi L, Macinko J. Contribution of primary care to health systems and health. Milbank Q 2005 Sep;83(3):457-502 [FREE Full text] [doi: 10.1111/j.1468-0009.2005.00409.x] [Medline: 16202000 ]

17. Gray DP, Freeman G, Johns C, Roland M. Covid 19: a fork in the road for general practice. BMJ 2020 Sep 28;370:m3709. [doi: 10.1136/bmj.m3709] [Medline: 32988832]

18. Helsedirektoratet, Direktoratet for e-helse. E-konsultasjon og triage hos fastlege [E-consultations and triage with the GP]. 2019. URL: https://www.helsedirektoratet.no/rapporter/e-konsultasjon-helsedirektoratet-og-direktoratet-for-e-helse [accessed 2021-01-25]

19. Helse-og omsorgsdepartementet. Oppfordrer helsetjenesten til å bruke videokonsultasjon [Encourages the health care service to use video consultation] 2020. URL: https://www.regjeringen.no/no/aktuelt/oppfordrer-helsetjenesten-til-a-bruke -videokonsultasjon/id2693883/ [accessed 2021-01-25]

20. Tikkanen R, Osborn R, Mossialos E, Djordjevic A, Wharton G. The Commonwealth Fund. International Health Care System Profils - Norway 2020. URL: https://www.commonwealthfund.org/international-health-policy-center/countries/norway [accessed 2021-01-25]

21. Car J, Koh GC, Foong PS, Wang CJ. Video consultations in primary and specialist care during the COVID-19 pandemic and beyond. BMJ 2020 Oct 20;371:m3945. [doi: 10.1136/bmj.m3945] [Medline: 33082127 ]

22. Eysenbach G. Improving the quality of Web surveys: the Checklist for Reporting Results of Internet E-Surveys (CHERRIES). J Med Internet Res 2004 Sep 29;6(3):e34 [FREE Full text] [doi: 10.2196/jmir.6.3.e34] [Medline: 15471760]

23. Norsk Helseinformatikk AS. URL: https://nhi.no/ [accessed 2021-01-25]

24. Helsedirektoratet, Fastlegestatistikk [Statistics for Norwegian General Practitioners]. URL: https://www.helsedirektoratet.no/ statistikk/fastlegestatistikk [accessed 2021-01-27]

25. Salisbury C, Quigley A, Hex N, Aznar C. Private Video Consultation Services and the Future of Primary Care. J Med Internet Res 2020 Oct 01;22(10):e19415 [FREE Full text] [doi: 10.2196/19415] [Medline: 32812887]

26. Donaghy E, Atherton H, Hammersley V, McNeilly H, Bikker A, Robbins L, et al. Acceptability, benefits, and challenges of video consulting: a qualitative study in primary care. Br J Gen Pract 2019 Jun 03;69(686):e586-e594. [doi: 10.3399/bjgp19x704141]

27. Haun MW, Stephan I, Wensing M, Hartmann M, Hoffmann M, Friederich H. Intent to Adopt Video-Based Integrated Mental Health Care and the Characteristics of its Supporters: Mixed Methods Study Among General Practitioners Applying Diffusion of Innovations Theory. JMIR Ment Health 2020 Oct 15;7(10):e23660 [FREE Full text] [doi: 10.2196/23660] [Medline: $\underline{33055058]}$

28. Johnsen T, Norberg B, Krogh F, Sigurdsson J, Getz L. Complex issues in general practice - a prevalence study. Tidsskr Nor Laegeforen 2020 Jun 30;140(10):1017-1022. [doi: 10.4045/tidsskr.19.0683] [Medline: 32602308]

29. Andrees V, Klein T, Augustin M, Otten M. Live interactive teledermatology compared to in-person care - a systematic review. J Eur Acad Dermatol Venereol 2020 Apr;34(4):733-745. [doi: 10.1111/jdv.16070] [Medline: 31715035]

30. Brinker TJ, Hekler A, von Kalle C, Schadendorf D, Esser S, Berking C, et al. Teledermatology: Comparison of Store-and-Forward Versus Live Interactive Video Conferencing. J Med Internet Res 2018 Oct 24;20(10):e11871 [FREE Full text] [doi: 10.2196/11871] [Medline: 30355564]

31. Chuchu N, Dinnes J, Takwoingi Y, Matin R, Bayliss S, Davenport C, Cochrane Skin Cancer Diagnostic Test Accuracy Group. Teledermatology for diagnosing skin cancer in adults. Cochrane Database Syst Rev 2018 Dec 04;12(12):CD013193 [FREE Full text] [doi: 10.1002/14651858.CD013193] [Medline: $\underline{\text { 30521686] }}$

32. Malterud K, Reventlow S, Guassora AD. Diagnostic knowing in general practice: interpretative action and reflexivity. Scand J Prim Health Care 2019 Dec 11;37(4):393-401 [FREE Full text] [doi: 10.1080/02813432.2019.1663592] [Medline: $\underline{31507239]}$

33. Greenhalgh T, Shaw S, Wherton J, Vijayaraghavan S, Morris J, Bhattacharya S, et al. Real-World Implementation of Video Outpatient Consultations at Macro, Meso, and Micro Levels: Mixed-Method Study. J Med Internet Res 2018 Apr 17;20(4):e150 [FREE Full text] [doi: 10.2196/jmir.9897] [Medline: 29625956]

34. Marshall M, Howe A, Howsam G, Mulholland M, Leach J. COVID-19: a danger and an opportunity for the future of general practice. Br J Gen Pract 2020 May 11;70(695):270-271. [doi: 10.3399/bjgp20x709937]

35. Salisbury C, Murphy M, Duncan P. The Impact of Digital-First Consultations on Workload in General Practice: Modeling Study. J Med Internet Res 2020 Jun 16;22(6):e18203 [FREE Full text] [doi: 10.2196/18203] [Medline: 32543441]

36. Newbould J, Abel G, Ball S, Corbett J, Elliott M, Exley J, et al. Evaluation of telephone first approach to demand management in English general practice: observational study. BMJ 2017 Sep 27;358:j4197 [FREE Full text] [doi: 10.1136/bmj.j4197] [Medline: 28954741]

37. Sinha S, Kern LM, Gingras LF, Reshetnyak E, Tung J, Pelzman F, et al. Implementation of Video Visits During COVID-19: Lessons Learned From a Primary Care Practice in New York City. Front Public Health 2020 Sep 17;8:514 [FREE Full text] [doi: 10.3389/fpubh.2020.00514] [Medline: 33042950] 
38. Hammersley V, Donaghy E, Parker R, McNeilly H, Atherton H, Bikker A, et al. Comparing the content and quality of video, telephone, and face-to-face consultations: a non-randomised, quasi-experimental, exploratory study in UK primary care. Br J Gen Pract 2019 Jul 01;69(686):e595-e604. [doi: 10.3399/bjgp19x704573]

39. Shaw SE, Seuren LM, Wherton J, Cameron D, A'Court C, Vijayaraghavan S, et al. Video Consultations Between Patients and Clinicians in Diabetes, Cancer, and Heart Failure Services: Linguistic Ethnographic Study of Video-Mediated Interaction. J Med Internet Res 2020 May 11;22(5):e18378 [FREE Full text] [doi: 10.2196/18378] [Medline: 32391799]

\section{Abbreviations \\ GP: general practitioner \\ VC: video consultation}

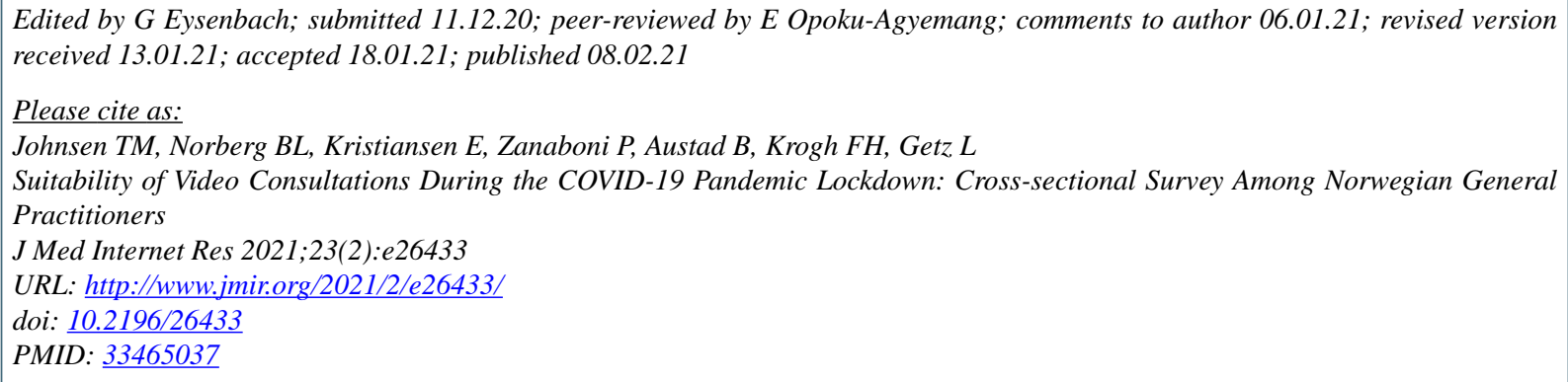

(CTor Magne Johnsen, Børge Lønnebakke Norberg, Eli Kristiansen, Paolo Zanaboni, Bjarne Austad, Frode Helgetun Krogh, Linn Getz. Originally published in the Journal of Medical Internet Research (http://www.jmir.org), 08.02.2021. This is an open-access article distributed under the terms of the Creative Commons Attribution License (https://creativecommons.org/licenses/by/4.0/), which permits unrestricted use, distribution, and reproduction in any medium, provided the original work, first published in the Journal of Medical Internet Research, is properly cited. The complete bibliographic information, a link to the original publication on http://www.jmir.org/, as well as this copyright and license information must be included. 